\title{
Using Modularity to Reduce Complexity of Industrialized Building Systems for Mass Customization
}

\author{
Daniela D. Viana ${ }^{1, *}$, Iris D. Tommelein ${ }^{2}$ and Carlos T. Formoso ${ }^{3}$ \\ 1 Interdisciplinary Department, Campus Litoral Norte, Universidade Federal do Rio Grande do Sul, \\ Tramandai 95590-000, Brazil \\ 2 Project Production Systems Laboratory, Department of Civil and Environmental Engineering, \\ University of California, Berkeley, CA 94720-1712, USA; tommelein@berkeley.edu \\ 3 Building Innovation Research Unit (NORIE), School of Engineering, Universidade Federal do Rio Grande \\ do Sul, Porto Alegre 90035-190, Brazil; formoso@ufrgs.br \\ * Correspondence: dietz.viana@ufrgs.br; Tel.: +55-51-3308-1332
}

Received: 17 September 2017; Accepted: 9 October 2017; Published: 17 October 2017

\begin{abstract}
It is widely known that industrialized building systems can positively impact construction projects in terms of efficiency, duration, safety, and quality. Although the use of industrialized building systems can potentially simplify the production process on-site, the complexity of the overall delivery system tends to be high, especially in engineered-to-order (ETO) environments, due to factors such as uncertainty related to goals and methods, conflicts between different trades on-site, and interdependence between supply chain members. This paper explores the concept of modularity, which has proven to be useful in different industries as a way of dealing with complex systems. The aim of this paper is to illustrate how modularity can reduce the complexity of ETO industrialized building systems, in companies that adopt a mass customization strategy. This investigation is based on two descriptive case studies on the development of modular structural steel systems for buildings that have adopted innovative beam-to-column connections. The main contribution of this research is demonstrating the need to adopt an integrated product and process-oriented conceptualization of modularity in industrialized building systems. Moreover, the comparison between the two case studies pointed out that the management of tolerances plays a key role in achieving high productivity and short lead times in structural steel building systems. This investigation also illustrates how the adoption of a limited set of modular components can be used to decouple design decisions, and standardize different types of processes.
\end{abstract}

Keywords: mass customization; modularity; integration; tolerances; industrialized building systems; steel structures; lean construction; connection

\section{Introduction}

Potential benefits of industrialized building systems in comparison to on-site stick-built systems include: increase in productivity [1], improvement in working conditions [2], better quality [3], reduction of construction waste [4], and higher sustainability performance [5].

Industrialization in construction is all too often viewed as using off-the-shelf mass-produced components that are fabricated off-site. Nevertheless, this term has evolved in the last few decades to support a broader view, including a range of technical and organizational innovations, as well as the supply chain and information-related aspects [6]. This change in the conceptualization of industrialization in construction is particularly important in engineered-to-order (ETO) production systems, in which a unique product must fulfill the requirements of specific clients [7]. In the delivery 
of ETO projects, the customer order is placed at the design stage [8], yet the customer also wants a lead time that is short, thus requiring some degree of overlapping between project stages [9].

Although industrialized building systems can potentially simplify the production process by reducing of the number of steps, parts, and linkages [10], the level of complexity in ETO industrialized building systems is usually high: (i) much uncertainty exists because it is necessary to define delivery dates in the early project stages, when the product is not yet completely defined [7]; (ii) as is the case on any other construction projects, unanticipated conflicts may arise between trades on-site during site installation [11]; (iii) the supply chain tends to be complex, involving several companies or business units [12]; and (iv) some resources, such as manufacturing plants, assembly equipment, and crews, must be shared among different construction projects [13]. Therefore, this type of production system fits the definition of project complexity proposed by Williams [14], which has two dimensions: (i) structural complexity (e.g., large number of tasks and interdependences); and (ii) uncertainty related to goals or methods.

A common mistake in the management of construction projects is to assume a high level of predictability, establishing goals according to long-term estimates of demand and performance [15]. The corresponding managerial practices, when applied to the delivery of industrialized building systems, tend to result in large inventories as the components are not produced and shipped to the construction site according to the assembly sequence, but instead following prioritization policies that favor resource utilization at the expense of lead time, such as the use of large batches and local optimization (e.g., of fabrication or freight) $[2,16]$. Another common mistake is that planning and control are carried out separately for each production phase (design, manufacturing/fabrication, logistics, and assembly) [13,17] by either different companies or divisions of a single company [18], sometimes using buffers to decouple their work [19]. This fragmentation tends to affect downstream flows. It makes the on-site assembly process less reliable due to delays in component delivery [13]. It also drives the need to solve problems related to mismatching of parts during site assembly [12], difficult-to-fabricate connections, and on-site struggling to plumb the structure [18].

The concept of modularity has proven to be useful in different types of systems as a way of dealing with complexity [20]. It is based on the idea of decomposing a system into functionally independent sub-systems, and then minimizing their interdependence [20]. It is concerned with the idea of dividing a product into manageable parts (modules) that use standard ways of interaction [21]. In fact, the literature suggests that the adoption of modularity brings a wide range of benefits: (i) simplification of the design process; (ii) increased product variety (customization) achieved by rearranging optional modules; (iii) economies of scale due to the use of components across product families; (iv) decreased order lead-time thanks to fewer components having to match downstream; and (v) maintenance and replacement of modules may be facilitated [21]. Therefore, while the problems arising during on-site production could be reduced by using prefabricated components, the problems that stem from using one-of-a-kind products could be alleviated by using pre-engineered and modularized products [22].

Product modularity is a key enabler of mass customization. The idea of the mass customization is to deliver products that have some degree of customization while striving to meet the standards of efficiency, cost, and quality of mass production [23]. It seeks to simultaneously achieve two seemingly conflicting goals: (i) high product variety; and (ii) high volume, by delivering products that fulfill the specific requirements of different customers through flexible processes and organizational structures [24].

The adoption of mass customization can further increase value by delivering products that are more environmentally and socially sustainable. The delivery of buildings tailored to specific requirements can potentially reduce waste resulting from the changes carried out by users after project completion (e.g., changes that may eventually lead to increases in energy consumption).

Although the benefits of product modularity (or use of a modular architecture) in product design have been widely discussed in the literature for different types of products and industries, its impacts on the life-cycle of real products is less clear [21]. Lehtonen et al. [25] state that product modularity cannot be regarded as an isolated strategy for product development, and suggest that the whole 
production system needs to be designed considering the potential benefits from modularization. Voordijk et al. [26] pointed out the importance of analyzing modularity in the construction industry from three perspectives: (i) product; (ii) process; and (iii) supply chain, based on a conceptualization proposed by Fine [27]. The aim of this paper is to illustrate how modularity can reduce the complexity of ETO industrialized building systems, specifically structural steel systems for building construction. The paper describes core operations management concepts and principles associated with the idea of modularity, including the elimination of non-value-adding activities (waste), standardization, batch size reduction, use of a platform architecture, tolerance management, and integration of production flow in the supply chain. It is based on two case studies on the development of modular structural steel systems that have adopted innovative beam-to-column connections.

\section{Role of Modularity in the Management of Complex Systems}

Modularity is a manifestation of the universal principle of economy in nature, which makes it possible to obtain diversity and variability by combining a set of basic elements [28]. However, there is a lack of consensus on the conceptualization of product modularity in the literature [21]. Different perspectives, languages, and definitions are discussed, from different fields of knowledge, such as engineering management, management science, and operations management [29]. Gershenson et al. [21] conclude there is neither a clear measure of product modularity nor a widely adopted systematic method to help designers to increase the degree of product modularity.

Based on Suh's [30] independence axioms, the modularity concept is often reduced to the relationship between functional and physical elements [31]. Functional elements refer to the individual operations and transformations that contribute to the overall performance achieved by the product, while physical elements are the parts that implement those functions [31]. This means that functional elements are enabled by a set of different physical elements, and physical elements are organized in blocks (product modules) that implement product functions. The organization of functional elements into physical modules and the way these modules interact is defined by the so-called architecture of the product. A product architecture is said to be more modular the fewer functions are implemented in each module, as well as the better defined the interaction is between them [20,31]. That is, achieving independence is the core intent in modular design. The opposite of a modular architecture is an integral architecture, where a complex relationship exists between functional and physical components, and the interfaces between them are coupled [32].

Gershenson et al. [21] bring a different perspective in the notion of modularity, observing that most of the applications of Suh's [30] independence axioms appear to have been for small sized problems. Chen et al. [33] found that, when designing a complex system, it becomes very difficult to track the application of those axioms.

Different definitions of complexity have in common the idea that complex systems have emergent behavior from interactions between parts of the system, which makes central control ineffective [34]. Emergence means that even when it is possible to understand the behavior of each component of the system, the collective behavior is hard to predict. In fact, Crichton [35] suggests that the interdependence between parts is also a source of uncertainty, since it makes it difficult to understand the impact of a single change in the whole project. Baldwin and Clark [20] identified three concepts related to modularity that provide some support in the management of complexity: (i) abstraction; (ii) information hiding; and (iii) interface. They suggest that modularization makes it possible to isolate a very complex part from the others: this complex part can be thought at a different level of abstraction, hiding some of its information while using a simple interface to the remaining parts.

Moreover, Gesherson et al. [36] suggest that designers should consider the life-cycle processes that components undergo, when dealing with a complex system, so that the benefits of modularity can be fully achieved [36]. Therefore, modularity can be applied for both products and processes, and a product should be designed considering the following three facets of modularity [36]: 
- Attribute Independence: Considering that component attributes depend less on the attributes of other modules, it is possible to re-design a module, with minimal effects on the rest of the product.

- Process Independence: The processes that involve the components of a module, in different life-cycle stages, depend less on the processes of external components. This makes it possible to re-design a module in isolation if a process must change.

- Process Similarity: Components and subassemblies that undergo the same or compatible life-cycle processes are combined in the same module. This minimizes the number of external components that undergo the same processes, and creates an even stronger differentiation between modules.

Fine et al. [37] offered yet another view by arguing that, like products, supply chains also have an architectural structure, ranging from integral to modular. An integral supply chain is one in which its members are in close proximity with each other, with proximity measured along the four dimensions of: (i) geography; (ii) organization; (iii) culture; or (iv) electronic connectivity. By contrast, a modular supply chain is one in which the members are highly dispersed geographically and culturally, and have few close organizational ties and only modest electronic connectivity [37].

\section{Modularity in the Construction Industry}

The three different perspectives of the modularity concept-product, process, and supply chain-are useful for discussing key differences between construction and manufacturing. From the product perspective, a difference between those two industrial contexts is related to how components are packed together. Most manufacturing products are simply divided into components, which have a central role in the definition of the product architecture, i.e., components are needed to perform specific functions and these functions contribute to the function of the product at the highest level. By contrast, only focusing on components is not appropriate for the construction industry, because buildings need to be considered as a mix of components and spatial voids [38], similarly to a few products in other industries, such as cars, ships and planes. In fact, the main function of a building, at the highest level, is not provided by components but by spatial voids for people.

From the process perspective, the notion of modules as mechanically stable sub-assemblies [29] is another underlying notion of modularity that is not completely applicable to buildings. In manufacturing, suppliers are able to deliver complex modules that require only simple assembly by the main manufacturer [39]. However, in most construction projects it is difficult to use this type of modules exclusively. Although mechanically stable modules can be applied in some highly industrialized projects (e.g., elevators and air conditioning systems), much construction work is still performed on-site, using traditional technologies, especially in phases such as excavation and foundation construction. In addition, the finishing phases are often postponed and completed on-site just prior to project turn-over, in order to avoid damage to the finished product, which may be caused by the production activities taking place inside the building. The need for on-site work is related to the unique character and immobility of buildings [40].

Finally, the unique and temporary nature of construction projects (akin to new product development in manufacturing) is another difficulty to the design and production of modules as stable sub-assemblies. Construction project supply chains are essentially temporary multi-organizations that are set up with the specific purpose of delivering a construction project. Such supply chains are established at the start of the project, develop, and finally disband as the end of it [41]. In contrast with manufacturing, suppliers have few opportunities or incentives to design and produce modules for a large number of projects. Due to building projects one-off nature, the modules developed for one project are unlikely to be suitable for other projects [42].

\section{Modularity and Prefabricated Building Systems}

Ethiraj and Levinthal [43] suggest that the benefits of modularity can be increased if other concepts related to industrialized construction are adopted, such as standardization and the use of 
platforms [6]. Standardization is concerned with the extensive and repetitive use of a solution that deals with recurring problems [31], being applicable to both product and process modularity. A platform (or chassis), in turn, refers to a common set of components, modules, or parts in order to provide derivative products [44]. Accordingly, buildings can be configured with components and parts from a platform into unique products, so that benefits are gained when the components of the platform are used to produce a variety of products with a common technological content [6]. Bonev et al. [45] also emphasize the importance of the use of platforms as a competitive advantage in the building industry, noting that several projects can share common platforms.

Another key concept in mass customization is the customer order decoupling point, i.e., the point in which the client order is placed in the supply chain, separating activities (downstream for that point) that are demand driven from activities (upstream for that point) that are forecast driven [46]. In manufacturing, this point separates activities of the supply chain that are pushed (forecast-driven) from those that are pulled (customer-driven).

In ETO, prefabricated building systems, the order penetration point is at the design stage. However, both the design and the production of prefabricated components should be pulled from site assembly [47] in order to keep a low level of work-in-progress, as well as to consider demand variability that typically arises during on-site assembly [13]. In fact, in some fast and complex projects, design changes are often demanded by clients and designers after production has already started [2]. In that context, Hopp and Spearman's [48] definition of pull production, i.e., the release work based on system status rather than schedule driven, applies.

Modularization is also strongly related to the core operations management principle of reducing the batch size, which can be related to product modularity (e.g., a single sub-assembly) or process modularity (e.g., a small number of processes that are necessary for installing a set of components). Batch size reduction has a positive impact in controlling the level of work-in-progress, reducing lead time, and early detection of deviations [49].

\section{Research Method}

Case study was the research strategy adopted in this investigation. It is preferred over other strategies when "how" and "why" research questions are being posed, when the researcher has little control over events, and when the focus is on a contemporary phenomenon within some real-life context [50]. The researchers conducted two descriptive case studies on the development of innovative structural steel systems, specifically involving beam-to-column connections, that have explored the concept of modularity.

The first case study refers to an early effort to develop a modular connection for structural steel systems involving beams that would "slide into place" during steel erection. This connection was developed at the Advanced Technology for Large Structural Systems (ATLSS) Centre at Lehigh University, USA. The authors chose this case because it had challenged the prevailing practice of steel erection and aimed to bring more automation into the construction process. There was a slight relationship between the two cases, although not affecting directly product development. According to ConXtech vice president, the firsts structural analyses of their system were carried out at the ATLSS Center.

The second case study refers to a beam-to-column connection system developed by Robert Simmons, who commercialized his invention by founding the ConXtech Inc (Pleasanton, California, USA). In fact, this innovation started with the development of the connection, and evolved into a commercial strategy for delivering customized structural steel systems. The authors chose this case because it too challenged the prevailing practice of steel erection. A Construction Industry Institute (CII) report [51] presented it as a benchmark for efficiency, speed, quality, and safety in the delivery of steel structures.

The researchers used multiple sources of evidence to document each case with the aim of increasing data reliability. In the first case study, as the system had been developed in the 1990s, the sources of evidence were: (i) secondary data obtained from research reports; and (ii) a 
semi-structured interview with a former research team member. In the second case study, sources of evidence were: (i) document analysis; (ii) secondary data obtained from published articles; (iii) three face-to-face semi-structured interviews with managers of the company; and (iv) three visits to the manufacturing plant. Table 1 presents the sources of evidence and the aim served by each.

Table 1. Sources of evidence for case studies.

\begin{tabular}{|c|c|c|}
\hline Case Study & Source of Evidence & Aim \\
\hline \multirow[b]{2}{*}{ ATLSS } & Research reports [18,52-55]. & $\begin{array}{l}\text { To get an overall understanding of the development of } \\
\text { the solution. }\end{array}$ \\
\hline & $\begin{array}{l}\text { Semi-structured interview with a } \\
\text { professor in the Leigh University, who } \\
\text { used to manage the ATLLS Center. }\end{array}$ & $\begin{array}{l}\text { To get additional details about the innovation and its } \\
\text { development, and to understand the relationship with } \\
\text { ConXtech's innovation. }\end{array}$ \\
\hline \multirow{4}{*}{ ConXtech Inc. } & $\begin{array}{l}\text { Document analysis (operations } \\
\text { instructions, scheduling documents). }\end{array}$ & $\begin{array}{l}\text { To understand the assembly process, and get data for the } \\
\text { duration of production activities, testing, and waiting. }\end{array}$ \\
\hline & Published articles $[56,57]$. & To analyse cost using secondary data. \\
\hline & $\begin{array}{l}\text { Three semi-structured interviews with } \\
\text { the president, vice-president, and the } \\
\text { production manager of the company. }\end{array}$ & $\begin{array}{l}\text { To understand how they managed production, and the } \\
\text { challenges faced in delivering their projects. }\end{array}$ \\
\hline & Three visits to the fabrication plant. & $\begin{array}{l}\text { To observe first-hand the production process and to collect } \\
\text { data about the amount of material stored on-site. }\end{array}$ \\
\hline
\end{tabular}

The researchers carried out these two case studies over a period of four months in 2014. At the end of this investigation, they compared the two innovations by focusing especially on the different types of modularity adopted.

\section{Beam-to-Column Connection Cases}

The components of the structural steel systems investigated in both case studies are columns, beams, and connections Adopting the perspective of product modularity, the steel structure of a building may be thought of, not as an integral design, but as a beam-to-column connection comprising a column module and a beam module. Depending on the design requirements, fabrication technologies, logistics constraints (such as the truck size) and on-site considerations, buildings often have beams and columns of variable shapes and dimensions.

Adopting another perspective, considering the requirements of the assembly process, spatial voids can be considered as modules, as suggested by Rocha et al. [38], i.e., a set of connections, columns, and beams that define a segment of the steel structure. Once a segment has been completed, other construction activities can take place, such as floor slab placement, installation of cladding, roofing, and erection of internal partitions. The size of the space modules depends on the batch sizes that are defined at the manufacturing plant, logistics stations, and site. When the project lead time is short, and uncertainty in the assembly process is high, there is usually a demand to work in small batches [58]. Therefore, process modularity, as described by Gesherson et al. [36], is important in the delivery of steel structures.

Beam-to-column connections must provide the necessary physical and performance characteristics for the structural steel system. Beams and columns are typically connected through drilled flanges, welded on the columns and bolted on the beams in place. The process of connecting beams to erected columns is a critical and dangerous part of the assembly process since it requires a crew for aligning beams in the correct position, while being exposed to the risk of movement or fall of those elements.

Using the conceptualization proposed by Ulrich [59], steel structures are considered more modular when they comprise a more standard set of components and a more standard interface between those components. This can be achieved in the design of the structural system, or by defining production or assembly batches that are repetitive. 


\subsection{Case Study 1: ATLSS}

The focus of the ATLSS center was on automated construction [55]. The idea was to facilitate the way structures were erected on site, by developing a new type of connection and automating assembly operations. The aim of the ATLSS Integrated Building Systems (AIBS) project was to develop structural systems that had low overall construction costs and, at the same time, were easy to erect and effective in resisting gravity and lateral loads $[18,54]$. An important goal of the AIBS research project was to achieve a safer construction environment, avoiding workers to position themselves at heights on limited solid footing and to deal with hanging steel components that weigh many times more than they do [52]. Therefore, the conception of this structural system also included the development of an automated robotic crane capable of assembling structures on site [52]. This crane was based on a Stewart platform, which consists of two platforms connected by a series of six individually controlled linkages [55].

In Figure 1, the ATLSS connection has a cone shaped protrusion, foot or tenon and a cone shaped basket, boot or mortise [18]. The size of the connections took into account the strength needed and ease of manufacture. The mortise guide was shop-welded to the column, while the tenon piece was bolted to the beam web by means of framing plates [52]. The tolerances considered in the design of the connections were based on normal assembly deviations deemed acceptable on construction sites [18]. Therefore, any shape of steel beam or column readily available in the market could be used.

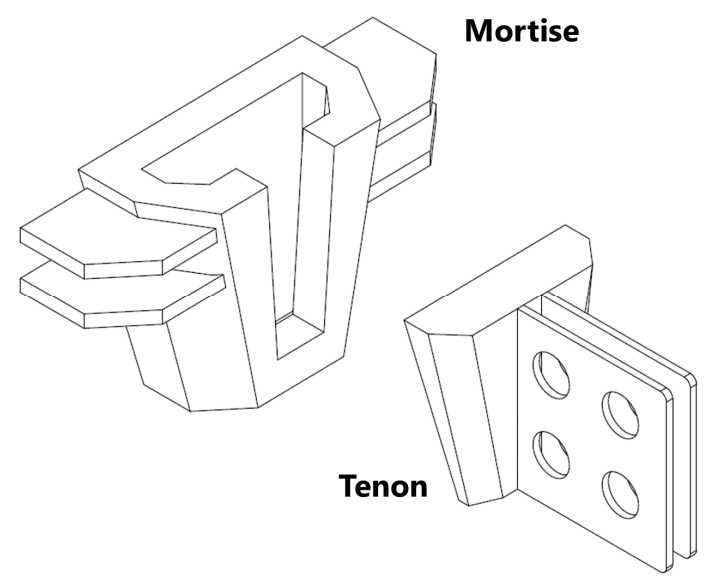

Figure 1. Advanced Technology for Large Structural Systems (ATLSS) beam-to-column connection.

Fleischman et al. [54] describe the features that were required when designing the ATLSS beam-to-column connection (Figure 1):

(i) Self-alignment: The connection must be able to guide the beam toward the proper location once the male and female pieces make contact. Furthermore, the male piece cannot jam or catch on the female guide, nor can it pull out horizontally once it engages.

(ii) Tolerances: The connection has no chance of succeeding if the male piece cannot enter the female guide. The connection must therefore have tolerances that allow some degree of misalignment or out-of-plumbness.

(iii) Adjustment: The connection must have the ability to be adjusted easily, as it is unlikely that the connection will be placed precisely in the correct position after erection, due to the tolerances which must be built in.

(iv) Strength and Stability: The connection must be strong enough to carry the erection loads, and it must be stable enough to allow erection of the structure to continue until the final fastening. As the connection is also a structural component, it must be able to carry the design loads.

(v) Modularity: the ultimate goal of this concept is to have a limited assortment of mass-produced connections with a standard shop fitting operation and quick, automatic erection capabilities. 
In a later study, changes were made to the structural system in order to make the connection moment-resistant. That upgrade required additional work, namely the installation of flanges after the beam is positioned in the structure [60]. This had a negative impact on the productivity of the assembly process.

The AIBS solution was never licensed by a company, nor was it applied commercially. The lack of commercial success of this structural system may be attributed to: (i) construction companies would have to use an expensive crane; and (ii) the overall efficiency of the assembly process was reduced due to the need for flanges. Nevertheless, the development of the ATLSS connection was a step towards understanding that the construction industry had not been using all the potential of modular structural systems to improve efficiency and safety.

\subsection{Case Study 2: ConXtech}

The motivation for developing the ConXtech system was to devise an efficient and safe method for producing multi-story buildings (up to 12 stories) [57]. The company president mentioned that he wanted to developed an industrialized structural system that was faster and more flexible than precast concrete structures. Assuming that the value of a structural system is not in the shape but in the functionality, all interviewees highlighted that the aim was to devise a highly modular system that could deliver mass-customized steel structures for a wide range of buildings.

The sections of the beams and columns are always of the same type: flange beams and squared columns, also called hollow-structural section (HSS) columns. ConXtech offers three different types of beam-to-column connections: ConXR (Figure 2a), ConXL (Figure 2b), and the gravity connection (Figure 2c). The differences between the ConXL and ConXR connections are the size of the section, and the clearances allowed.

The beam-to-column connections allow the self-alignment of beams using a gravity stabilized joint [57]. In each section, the connection creates a collar to distribute the force from the beam evenly to the perimeter of the column. An important characteristic of this structural system is that it overcomes the requirement for bracing or shear walls: the structural frame becomes a chassis comprised of a finite set of components [61]. This is possible due to the collar formed around the column, increasing the moment-resisting performance of the structure.

While ConXR has a single component welded to the column, which constrains the depth of the beam to the connection height, ConXL fits different heights. The latter connector is divided into two pieces welded to the beam, and another pair to the column, working as a trail to fit different dimensions. There are also gravity connections, used when no moment resistance is needed, e.g., around the perimeter of a building where there is less tributary load.

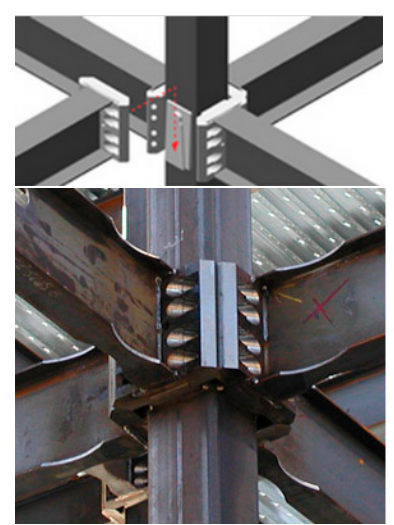

(a) ConXR connnection

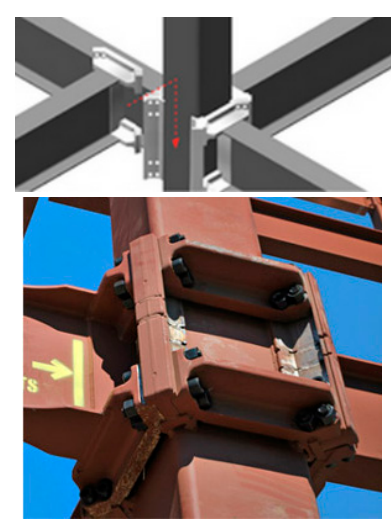

(b) ConXL connection

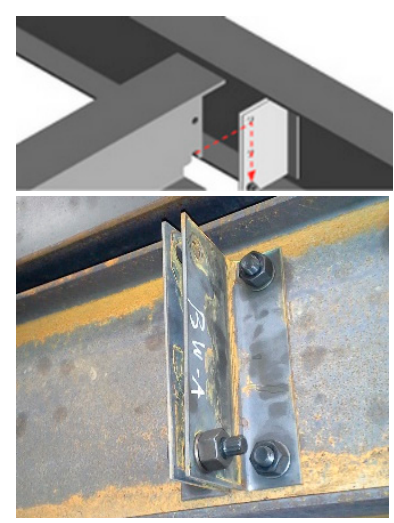

(c) Gravity connection

Figure 2. Types of connections from ConXtech (Source: ConXtech, used with permission from Kelly Luttrell). 
A major challenge of using such a precise connection system is the allowable tolerances in the foundations where the columns should be placed. The solution adopted by the company was to decouple the uncertain and inaccurate foundation location, by using a jig to precisely position the anchors at the foundation, as shown in Figure 3.

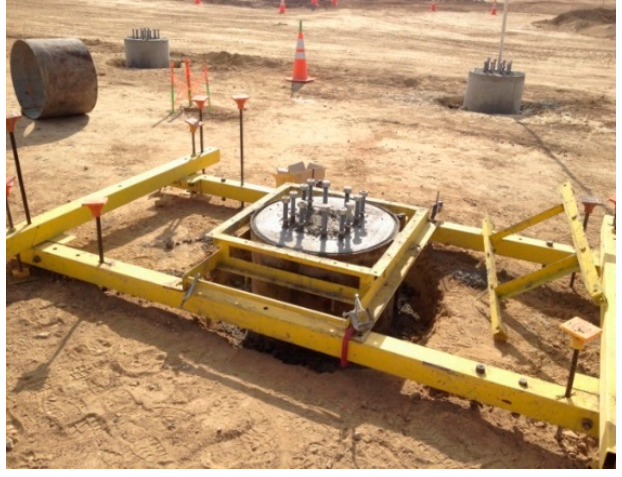

(a) Example of the jigs in place

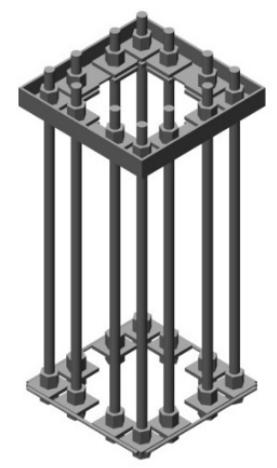

(b) Illustration of the anchor system

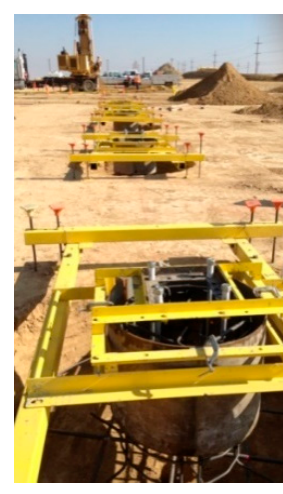

(c) Set of jugs aligned in place

Figure 3. Jigs to position the anchors at the foundations (Source: ConXtech, used with permission from Kelly Luttrell).

After the anchors are in place, columns are delivered and erected, one by one. Then, the interior of each column is filled with concrete to enhance strength and stability. Once columns are ready, beams are fit in-between them. At this point, the structure becomes stable, and the workers can start bolting. It is worth mentioning that the building is erected at full height in small batches (process modules) - rather than floor by floor, one full floor at a time-so that part of the structure can be released to the follow-on trades. During the erection process, there is no need for field welding. Moreover, the bolting process has a visual aid to avoid variability in the bolt tensioning. It consists of a washer with bumps, with orange silicone embedded in the depressions under the bumps. The worker should tighten the bolt until the calibrated amount of orange silicone appears. Therefore, only visual inspection is required, which reduces rework.

The company is able to offer four different types of solutions: ConXR 100, ConXR 200, ConXL 300, and ConXL 400. The number stands for the dimension of the square column in millimetres. Each system is supplemented with the use of gravity beams, where required. All connections are able to support a building up to 12 stories. The ConXR systems are ideal for 4-8 stories, while the ConXL system for 2-10. According to the company records, the productivity of erection is higher in ConXL systems since it covers larger spans, as shown in Table 2.

Table 2. Characteristics of the ConXR and ConXL connection types.

\begin{tabular}{|c|c|c|c|c|c|}
\hline \multicolumn{2}{|c|}{ Connection type } & \multirow{2}{*}{\begin{tabular}{l}
\multicolumn{1}{c}{ Ideal for } \\
Small scale pipe rack structures and \\
platforms for automated pallet \\
retrieval systems
\end{tabular}} & \multirow{2}{*}{$\begin{array}{l}\text { Column Size } \\
100 \mathrm{~mm}\end{array}$} & \multirow{2}{*}{$\begin{array}{l}\text { Beam Depth } \\
6 \text { (variable } \\
\text { weight) }\end{array}$} & \multirow{2}{*}{$\begin{array}{c}\text { Beam Spans } \\
4^{\prime} \text { to } 16^{\prime}\end{array}$} \\
\hline ConXR & CONXR 100 & & & & \\
\hline & CONXR 200 & $\begin{array}{l}\text { High-density residential and pipe } \\
\text { rack projects. }\end{array}$ & $200 \mathrm{~mm}$ & $\begin{array}{l}12 " \text { (variable } \\
\text { weight) }\end{array}$ & $8^{\prime}$ to $20^{\prime}$ \\
\hline \multirow[b]{2}{*}{ ConXL } & CONXL 300 & $\begin{array}{l}\text { High-density residential and pipe } \\
\text { rack projects }\end{array}$ & $300 \mathrm{~mm}$ & $14^{\prime \prime}$ to $24^{\prime \prime}$ & $12^{\prime}$ to $30^{\prime}$ \\
\hline & CONXL 400 & $\begin{array}{l}\text { Healthcare, military, data centre, } \\
\text { commercial office, institutional, } \\
\text { R\&D, parking and processing } \\
\text { structures for industrial and energy } \\
\text { \& natural resource applications. }\end{array}$ & $400 \mathrm{~mm}$ & $\begin{array}{l}18^{\prime \prime} \text { to } 30^{\prime \prime} \text { for } \\
\text { SMF and deeper } \\
\text { for OMF }\end{array}$ & $18^{\prime}$ to $>45^{\prime}$ \\
\hline
\end{tabular}


The use of common shapes and sizes of structural elements was part of the company strategy to get easy supply of raw materials. The angle between columns and beam starts from $90^{\circ}$ and can be increased in $7^{\circ}$ increments horizontally or vertically. Figure 4 illustrates the wide range of different structures that can be built using this system. A modular design enabled the company to create a platform for producing the structural components, with a limited set of options, yet still allowing an unlimited number of design configurations.

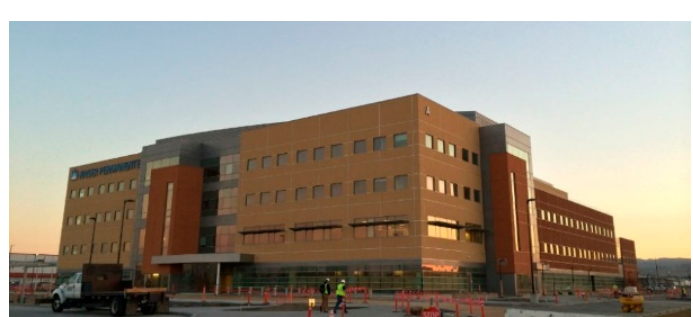

(a) Hospital project

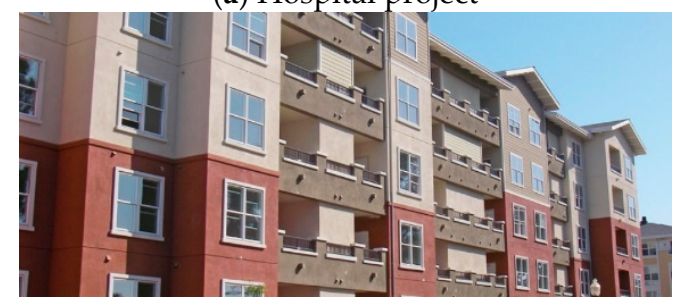

(c) Residential Project

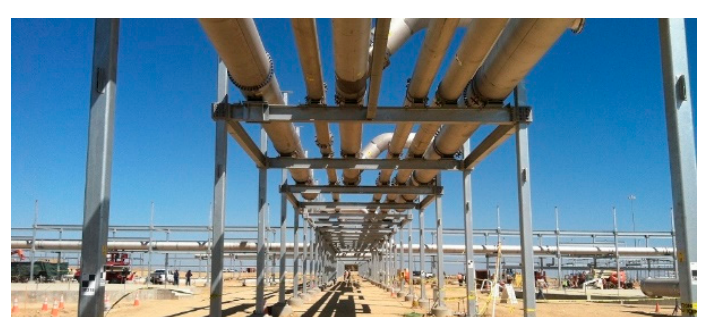

(b) Pipe rack

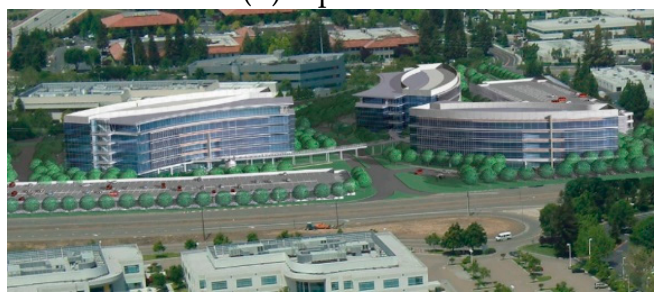

(d) Office building

Figure 4. Examples of projects using ConXtech structural steel (Source: ConXtech, used with permission from Kelly Luttrell).

Different from the ATLSS solution, the strategy adopted by ConXtech was to devise a very specific type of structural system with standardized component types, which establishes a number of design constraints. Those constraints could make ConXtech systems appear inferior in comparisons to some traditional structural systems that are more flexible in terms of dimensions. In order to facilitate the selection and specification of the company products by designers and structural engineers, ConXtech developed a BIM components library of their products that can be used by different BIM applications, such as Revit, ArchiCAD, and Tekla. This library makes it easier to develop designs in conformance with the structural system constraints, enabling designers to test product specification from the early stages of the design process, avoiding clashes and rework. In addition, after extensive testing in their fabrication shop, the ConXtech system was accepted in the AISC Steel Manual and OSHPD [62]. Considering the fragmentation of the construction supply chain, particularly between design and production phases, the development of partnerships with designers that are able to use this solution and with regulatory agencies was considered to be a key strategy.

A major consequence of the modular design, facilitated by the use of BIM, is the reduction of design lead times, and the reduction in rework that otherwise is necessary for turning schematic design into shop drawings to be used in the manufacturing process. Modularity also enables the company to provide timely cost estimates for projects. In an ETO environment, in which the customer demands cost and time estimates at the tender stage of the project [7,63], producing accurate estimates at early design represents a significant competitive advantage.

Cost and productivity was compared between the technology from ConXtech and conventional structural steel, and presented in a research report produced by the Construction Industry Institute (CII) [50], considering the processes shown in Figure 5. Data from nine different projects from ConXtech were used as evidence. The results indicated that the conventional method required a larger number of production steps: there is a need to make a first alignment, then installing temporarily bracing, to finally make the permanent connection. By contrast, in the ConXtech system the process 
was less complex, once the top beam is placed, the connection locks the structure into place, enabling worker to make the subsequent bolting quicker.

Conventional Method

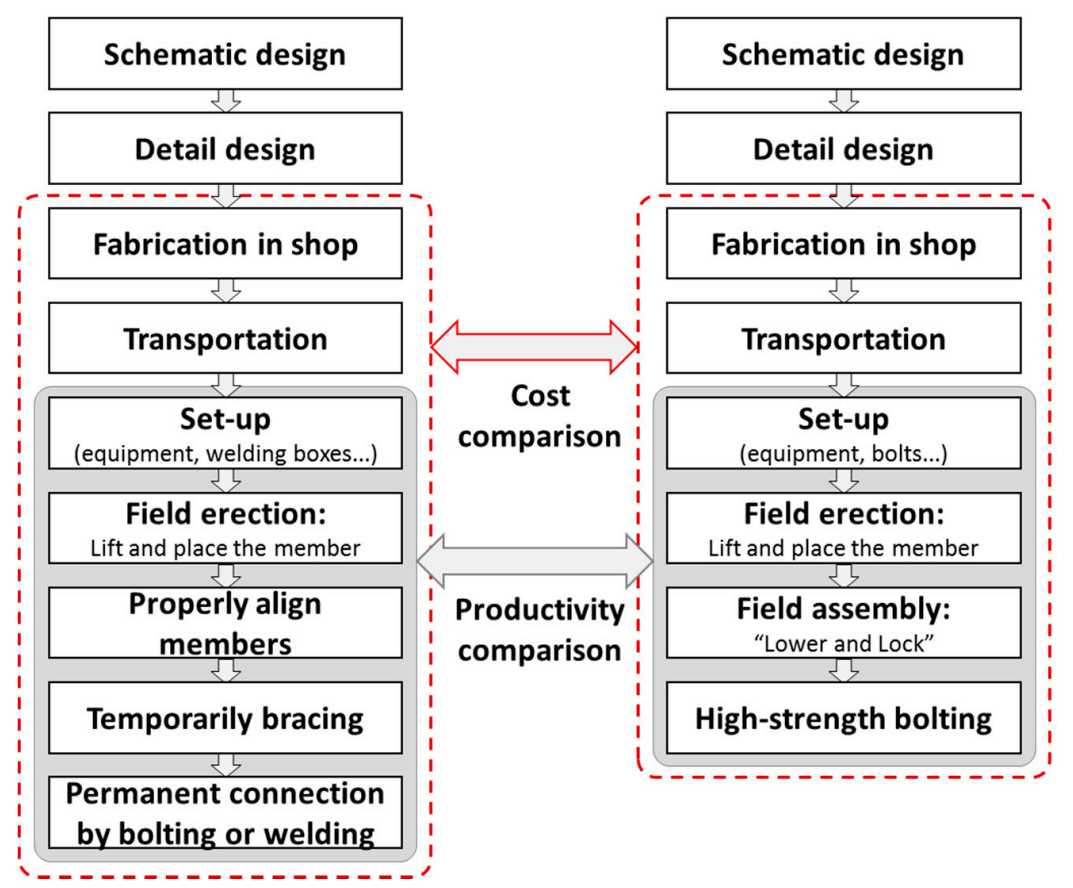

Figure 5. Differences in production process between the conventional structural steel and the ConXtech system.

Figure 6 shows the results of the comparative analysis regarding cost and productivity from Goodrum et al. [50]. The unit used to measure productivity was man-hours per tons produced. These data indicate that the productivity of ConXtech's projects is much higher than conventional structural steel erection methods, while the costs are almost the same. This is because the fabrication process of this system is more expensive than the traditional process: the ConXtech system demanded the acquisition of highly precise $\mathrm{CNC}$ machines to position connections in the right place. Consequently, there is more control over resources and over the lead time for the assembly process.

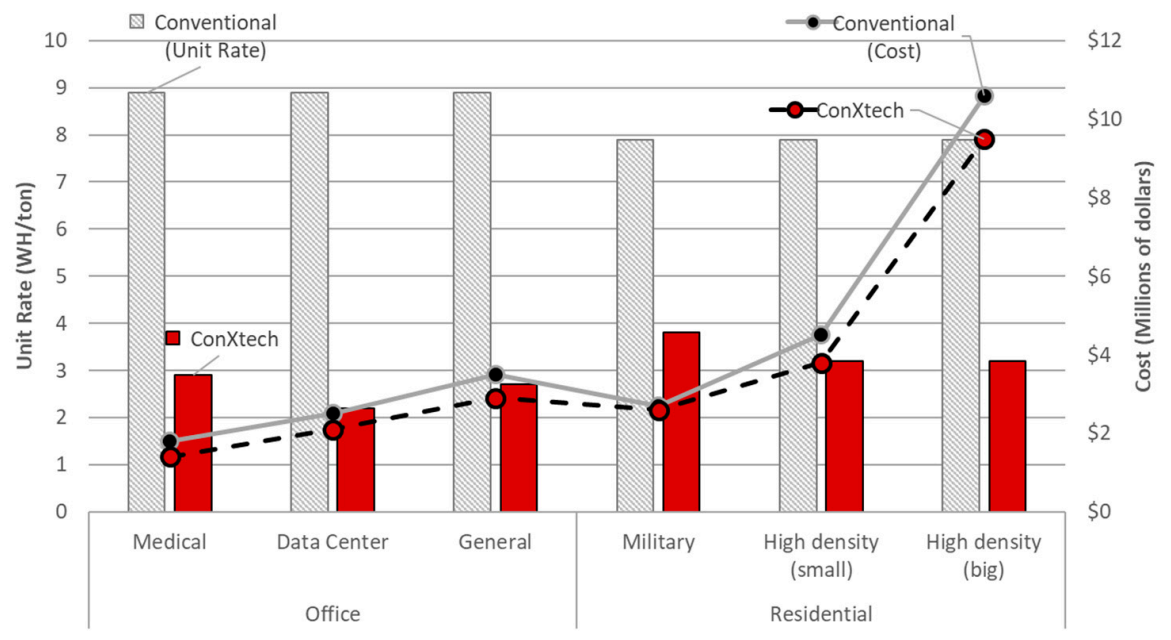

Figure 6. Productivity and cost comparison between ConXtech Inc. and RS MEANS (An institution from USA that provides cost information to the construction industry). 
A major advantage of the ConXtech solution is the short lead time for the company managers, this is one of the key competitive strategies of this company. Figure 7 depicts a typical schedule of a 3-story building of $5.000 \mathrm{~m}^{2}$ (five thousand square meters). It shows that phases overlap and it highlights the short time spent on site assembly relative to the overall project duration. A short lead time is of value to builders using ETO prefabricated building systems, because it enables the production of components to be pulled by the assembly process.

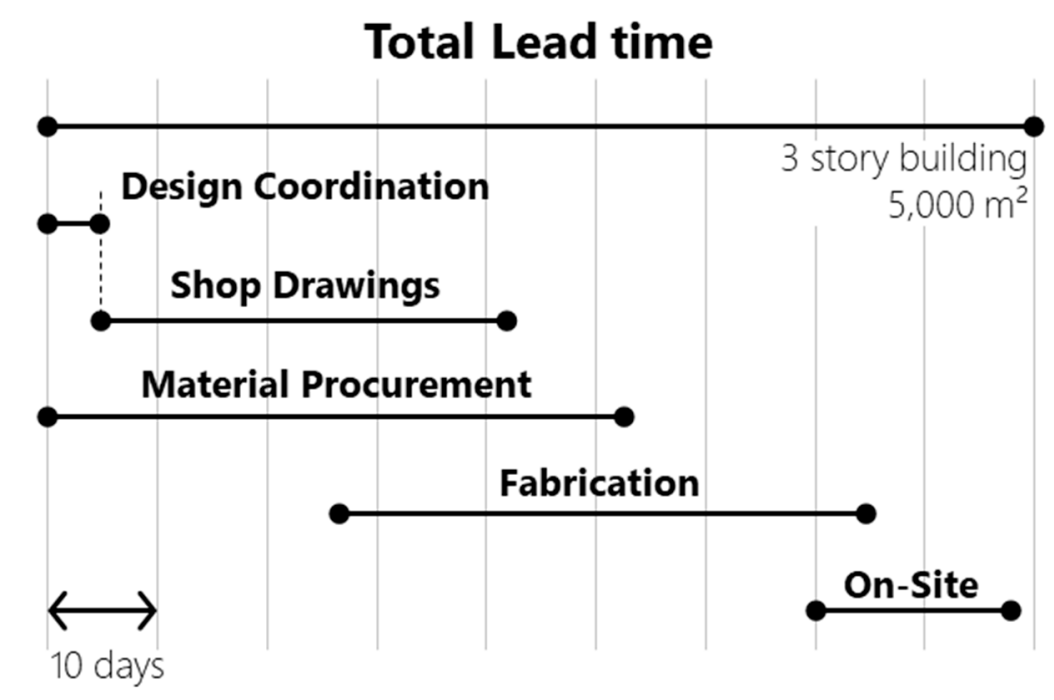

Figure 7. Typical project schedule of a ConXtech project (Source: authors).

\section{Discussion}

Although the two case studies showed similarities in terms of the structural components adopted in each respective system, major differences were identified regarding the way modularity was used.

In terms of product modularity, both systems have a beam-to-column connection that fits the concept of component-sharing module, i.e., a common component that can be adapted to different configurations [64]. Beams and columns in both systems can be categorized as cut-to-fit type modularity. These can have a standardized cross-section but the length is adapted to suit the design requirement [64].

Regarding supply chain modularity, both systems can be considered as modular, as steel beam and column can be produced by different suppliers, dispersed geographically, without necessarily having close organizational ties with the company that delivers steel structures, as suggested by Fine [37]. In fact, due to the type of connection used, beams and columns can be regarded to some extent as commodities, reducing the structural complexity of the system.

Two main differences between the two solutions were found: process modularity and the strategy for managing tolerances. Table 3 depicts characteristics of each connection, emphasizing the differences that made the final systems to become so different from one another.

Regarding attribute independence, ATLSS devised one type of connection for the interface of almost any type of beam with any type of column. A variation in the beam height, for example, would not change attributes of the columns, unless in the case of an overload. By contrast, ConXtech devised a system with great dependence among components, as the type and size of the connections were dependent on the beam height. Moreover, a limited set of connections, beams and columns are used, and these are standardized across different projects.

It is worth noting that, in the ATLSS system, it is possible to design the structure with the exact dimensions required. By contrast, in the case of ConXtech, structural component dimensions may sometimes be overestimated to fit available options, due to the limited range of suitable component types, but there are advantages in terms of reducing the lead time to find the best solution. 
As postulated by Baldwin and Clark [20], problems are decoupled, facilitating the decision-making process: some dimensions of the structural steel system are previously defined and the design problem is reduced to a matter of adapting a pre-conceived solution. As suggested by Rudberg and Wikner [65], decoupling design problems is an important example of how modularity deals with complexity in mass customization.

Table 3. Comparison between ATLSS and ConXtech systems.

\begin{tabular}{|c|c|c|}
\hline Characteristic & ATLSS & ConXtech \\
\hline Attribute independence & Little dependence among components. & Strong dependence among components. \\
\hline Process independence & $\begin{array}{l}\text { Absorb process variation by adjusting } \\
\text { the steel structure during erection. }\end{array}$ & $\begin{array}{l}\text { Decouple process variation from external } \\
\text { processes through control and } \\
\text { standardization of interfaces. }\end{array}$ \\
\hline Process similarity & $\begin{array}{l}\text { Little standardization as any type of } \\
\text { beam and column can be used. }\end{array}$ & Highly standardized process. \\
\hline Strength and Stability & $\begin{array}{l}\text { Strong enough to carry the erection } \\
\text { loads. Additional tasks are required to } \\
\text { make the connection moment resistant. }\end{array}$ & Moment and seismic-resistant. \\
\hline Tolerances & $\begin{array}{l}\text { Connections must have tolerances that } \\
\text { allow for alignment (consistent with } \\
\text { the structure being erected). }\end{array}$ & $\begin{array}{l}\text { Connection must be precisely positioned in } \\
\text { place, using accurate welding machines } \\
\text { and mistake-proof systems on the } \\
\text { construction site. The bolting process has a } \\
\text { visual aid to avoid variability. }\end{array}$ \\
\hline Adjustment & $\begin{array}{l}\text { Connections must have the ability to } \\
\text { be adjusted easily. }\end{array}$ & No room (no need) for adjustments. \\
\hline Equipment required for assembly & Automated cranes. & Ordinary cranes. \\
\hline
\end{tabular}

In both cases, a high level of process independence existed in the delivery of steel components. Structural components (beams and columns) and connections could be produced separately, even using different suppliers, as mentioned above. Moreover, both systems adopted a connection relying on self-alignment of beams.

However, regarding site assembly, ConXtech developed an effective solution to decouple the erection of the columns and the position of foundations, a jig that works as a template to place the anchors correctly. This reduces structural complexity, avoiding the need to exercise rigorous and expensive control over an uncertain process such as foundation construction. By contrast, the ATLSS system accepted normal deviations in the position of foundations, which affected the precision of the assembly process.

Process similarity was a concept explored only by ConXtech because the range of components adopted was limited, i.e., there was a high degree of repetition in the process modules used across different projects. In fact, ConXtech had exercised much effort for standardizing processes, even the non-physical ones, such as design. By contrast, in the case of ATLSS, production processes are more difficult to standardize, as connections can be attached to distinct types of components, requiring distinct processes. Clearly, ConXtech developed a more robust concept, considering modularity as a process-oriented concept, with the aim of getting the full benefits of modularity, as suggested by Gershenson et al. [21].

Regarding the management of tolerances, in the conception of the ATLSS solution, tolerances were considered as an inherited property of the structural steel system, i.e., the beam-to-column connection allowed a higher level of tolerance than the structural elements that were connected. Based on this assumption, the connection could be adapted to almost any kind of structural steel system. However, this has compromised strength and stability during the assembly process, and it was necessary to perform additional adjustment tasks. By contrast, ConXtech conceived of a production system with less uncertainty, in which the tolerance problem was tightly controlled, ensuring stability when components are put in place, and also a moment-resistant connection. The ConXtech system does not require adjustments in place, as the process is precisely controlled to avoid problems during 
the assembly process. A benefit of using this strategy for dealing with tolerances was the reduction in service costs [21] and in the site assembly lead time.

Finally, regarding the equipment necessary for the assembly process, the ATLSS system required a highly automated crane, with the aim of reducing the exposure of workers to the risk of accidents. The high cost of this equipment was one of the main reasons for the lack of commercial interest in this system. By contrast, in the ConXtech system, the same cranes used traditionally for structural steel erection can be used, and the strategy for preventing accidents was to reduce the length of time workers were exposed to risks.

\section{Conclusions}

This paper has contributed to the understanding of how modularity can reduce the complexity of ETO industrialized building systems, based on two case studies from companies that devised modular structural steel systems. Although the two systems were somewhat similar in terms of product modularity and supply chain modularity, they were very different regarding process modularity.

The process-oriented conceptualization of modularity, as suggested by Fine et al. [37], helps to rationalize the success of the ConXtech system. Based on the idea of managing life-cycle processes, proposed by Gershenson et al. [36], some useful constructs, such as process attributes and process similarities were used to understand a broader meaning of modularity that is applicable to industrialized building systems.

This investigation also explained why it is important to reduce the range of modular components used to devise a solution to the final client, as adopted in the ConXtech case. Besides decoupling key design decisions, that system created a platform solution, which enabled the standardization of different types of processes (including design). Moreover, the company has been able to fulfill the requirements of a wide range of clients, at no additional cost and with a very short lead time, compared to traditional solutions. This is a good example of how modularity can reduce complexity in ETO prefabricated building systems, which is very important in mass customization.

Moreover, the comparison between the two case studies pointed out that the management of tolerances plays a key role regarding reducing the number of steps in the assembly process, as well as rework, having a positive impact in terms of increasing productivity and reducing the lead time in industrialized building systems.

Therefore, five different strategies related to product and process modularity have been used in the ConeXtech system for reducing complexity: (i) decoupling design problems, by using components that have previously defined dimensions; (ii) reducing the number of parts and steps in the assembly process; (iii) decoupling construction problems, such as location of foundation and structural steel erection; (iv) by using a modular supply chain, beams and columns can be regarded to some extent as commodities; and (v) by controlling tolerances tightly, uncertainty was reduced.

Overall, this investigation reinforces the idea that modular solutions enable the adoption of a mass customization in ETO prefabricated building systems, but pointed out that modularity in that context is not limited to product architecture.

Further work is necessary on the application of this broad conceptualization of modularity in the context of construction projects that involve several industrialized building systems, which need to be integrated. It is important also to consider that, in many projects, industrialized building systems are combined with traditional construction technologies, and this should be considered in the adoption of the modularity concept. Moreover, some supply chain issues need to be tackled, considering that construction projects usually have temporary supply chains and that most industrialized building systems do not fit the category of modular supply chain members.

Acknowledgments: This study was supported in part by CNPq (National Council Scientific and Technological Development), from Brazil, and in part by members of the Project Production Systems Laboratory (P2SL) at UC Berkeley. Any opinions, findings, and conclusions or recommendations expressed in this material are those of the authors and do not necessarily reflect the views of CNPq or members of P2SL. 
Author Contributions: All three authors were involved in the writing of the paper. Daniela Viana and Iris Tommelein devised the research design, and Daniela Viana carried out data collection and processing.

Conflicts of Interest: The authors declare no conflict of interest.

\section{References}

1. Jansson, G.; Johnsson, H.; Engström, D. Platform use in systems building. Constr. Manag. Econ. 2014, 32, 70-82. [CrossRef]

2. Matt, D.T.; Dallasega, P.; Rauch, E. Synchronization of the manufacturing process and on-site installation in ETO companies. Procedia CIRP 2014, 17, 457-462. [CrossRef]

3. Zabihi, H.; Habib, F.; Mirsaeedie, L. Definitions, concepts and new directions in industrialized building Systems (IBS). KSCE J. Civ. Eng. 2013, 17, 1199-1205. [CrossRef]

4. Lachimpadi, S.K.; Pereira, J.J.; Taha, M.R.; Mokhtar, M. Construction waste minimisation comparing conventional and precast construction (Mixed System and IBS) methods in high-rise buildings: A Malaysia case study. Resour. Conserv. Recycl. 2012, 68, 96-103. [CrossRef]

5. Chen, Y.; Okudan, G.E.; Riley, D.R. Decision support for construction method selection in concrete buildings: Prefabrication adoption and optimization. Autom. Constr. 2010, 19, 665-675. [CrossRef]

6. Lessing, J. Industrialised House-Building: Concept and Processes; Department of Construction Sciences, Lund University: Lund, Sweden, 2006.

7. Bertrand, J.W.M.; Muntslag, D.R. Production control in engineer-to-order firms. Int. J. Prod. Econ. 1993, 30-31, 3-22. [CrossRef]

8. Gosling, J.; Naim, M.M. Engineer-to-order supply chain management: A literature review and research agenda. Int. J. Prod. Econ. 2009, 122, 741-754. [CrossRef]

9. Grabenstetter, D.H.; Usher, J.M. Sequencing jobs in an engineer-to-order engineering environment. Prod. Manuf. Res. 2015, 3, 201-217. [CrossRef]

10. Koskela, L. Application of the New Production Philosophy to Construction; Stanford University: Stanford, CA, USA, 1992.

11. Trebbe, M.; Hartmann, T.; Dorée, A. 4D CAD models to support the coordination of construction activities between contractors. Autom. Constr. 2015, 49, 83-91. [CrossRef]

12. Tommelein, I.D. Pull-driven scheduling for pipe-spool installation: Simulation of a lean construction technique. J. Constr. Eng. Manag. 1998, 124, 279-288. [CrossRef]

13. Viana, D.D.; Bulhoes, I.; Formoso, C.T. Guideliens for integrated planning and control of engineer-to-order prefabrication systems. In Proceedings of the 21st Annual Meeting of the International Group for Lean Construction, Fortaleza, Brazil, 29 July-2 August 2013; pp. 549-558.

14. Williams, T.M. The need for new paradigms for complex projects. Int. J. Proj. Manag. 1999, 17, $269-273$. [CrossRef]

15. Koskela, L.; Howell, G. The underlying theory of project management is obsolete. In Proceedings of the PMI Research Conference, Seattle, WA, USA, June 2002; pp. 293-302.

16. Ballard, H.G.; Harper, N.; Zabelle, T. Learning to see work flow: An application of lean concepts to precast concrete fabrication. Eng. Constr. Archit. Manag. 2003, 10, 6-14. [CrossRef]

17. Elfving, J.A.; Tommelein, I.D.; Ballard, H.G. Improving the Delivery Process for engineered-to-order products-Lessons learned from power distribution equipment. In Proceedings of the 12th Annual Conference on Lean Construction, Helsinor, Denmark, 3-5 August 2004.

18. Perreira, N.D.; Fleischman, R.B.; Viscomi, B.V.; Lu, L.-W. Automated Construction and ATLSS Connections; Development, Analysis, Experimentation, and Implementation of ATLSS Connections for Automated Construction, 1993. ATLSS Reports. ATLSS Report Number 93-02. Available online: http:/ / preserve.lehigh. edu/engr-civil-environmental-atlss-reports/183 (accessed on 1 December 2014).

19. Tommelein, I.D.; Weissenberger, M. More Just-In-Time: Location of buffers in structural steel. In Proceedings of the 7th Annual Conference of the International Group for Lean Constructionof the International Group for Lean Construction, Berkeley, CA, USA, 26-28 July 1999; pp. 109-120.

20. Baldwin, C.Y.; Clark, K.B. Design Rules: The Power of Modularity; Design Rules; MIT Press: Cambridge, MA, USA, 2000; Volume 1, ISBN 026-2-024-667. 
21. Gershenson, J.K.; Prasad, G.J.; Zhang, Y. Product modularity: Definitions and benefits. J. Eng. Des. 2003, 14, 295-313. [CrossRef]

22. Segerstedt, A.; Olofsson, T. Supply chains in the construction industry. Supply Chain Manag. Int. J. 2010, 15, 347-353. [CrossRef]

23. MacCarthy, B.; Brabazon, P.G.; Bramham, J. Fundamental modes of operation for mass customization. Int. J. Prod. Econ. 2003, 85, 289-304. [CrossRef]

24. Pine, B.J. Mass customizing products and services. Plan. Rev. 1993, 21, 6-55. [CrossRef]

25. Lehtonen, T.; Juuti, T.; Pulkkinen, A.; Riitahuhta, A. Dynamic modularisation-a challenge for design process and product architecture. In Proceedings of the 14th International Conference on Engineering Design (ICED 03), Stockholm, Sweden, 19-21 August 2003; p. 10.

26. Voordijk, H.; Meijboom, B.; Haan, J. Modularity in supply chains: A multiple case study in the construction industry. Int. J. Oper. Prod. Manag. 2006, 26, 600-618. [CrossRef]

27. Fine, C.H. Clockspeed-based strategies for supply chain design. Prod. Oper. Manag. 2009, 9, $213-221$. [CrossRef]

28. Jablan, S. Modularity in Art. Available online: http://www.mi.sanu.ac.rs/ jablans/d3.htm (accessed on 20 August 2017).

29. Salvador, F. Toward a product system modularity construct: Literature review and reconceptualization. IEEE Trans. Eng. Manag. 2007, 54, 219-240. [CrossRef]

30. Suh, N.P. Development of the science base for the manufacturing field through the axiomatic approach. Robot. Comput. Integr. Manuf. 1984, 1, 397-415. [CrossRef]

31. Ulrich, K.T.; Eppinger, S.D. Product Design and Development; McGraw-Hill/Irwin: New York, NY, USA, 2004; ISBN 978-0-07-247146-5.

32. Ulrich, K. The role of product architecture in the manufacturing firm. Res. Policy 1995, 24, 419-440. [CrossRef]

33. Chen, W.; Rosen, D.; Allen, J.K.; Mistree, F. Modularity and the independence of functional requirements in designing complex systems. Concurr. Prod. Des. 1994, 74, 31-38.

34. Mitchell, M. Complexity: A Guided Tour; Oxford University Press: New York, NY, USA, 2009; ISBN 978-0-19-974102-1.

35. Crichton, C. Interdependence and Uncertainty: A Study of the Building Industry; Tavistock Publications: London, UK, 1966; ISBN 113-6-42-977-8.

36. Gershenson, J.K.; Prasad, G.J.; Allamneni, S. Modular product design: A life-cycle view. J. Integr. Des. Process Sci. 1999, 3, 1-9.

37. Fine, C.H.; Golany, B.; Naseraldin, H. Modeling tradeoffs in three-dimensional concurrent engineering: A goal programming approach. J. Oper. Manag. 2005, 23, 389-403. [CrossRef]

38. Rocha, C.; Formoso, C.; Tzortzopoulos, P. Adopting Product Modularity in house building to support mass customisation. Sustainability 2015, 7, 4919-4937. [CrossRef]

39. Alford, D.; Sackett, P.; Nelder, G. Mass customisation-An automotive perspective. Int. J. Prod. Econ. 2000, 65, 99-110. [CrossRef]

40. Koskela, L. On theory of production in economics and production management. In Modern Construction Economics: Theory and Application; de Valence, G., Ed.; Spon Press: Abingdon, UK, 2011; pp. 80-99, ISBN 020-3-92-689-7.

41. Cherns, A.B.; Bryant, D.T. Studying the client's role in construction management. Constr. Manag. Econ. 1984, 2,177-184. [CrossRef]

42. Hofman, E.; Voordijk, H.; Halman, J. Matching supply networks to a modular product architecture in the house-building industry. Build. Res. Inf. 2009, 37, 31-42. [CrossRef]

43. Ethiraj, S.K.; Levinthal, D. Modularity and innovation in complex systems. Manag. Sci. 2004, 50, 159-173. [CrossRef]

44. Meyer, M.H.; Lehnerd, A.P. The Power of Product Platforms; Free Press: New York, NY, USA, 1997; ISBN 978-0-68-482580-9.

45. Bonev, M.; Wörösch, M.; Hvam, L. Utilizing platforms in industrialized construction: A case study of a precast manufacturer. Constr. Innov. 2015, 15, 84-106. [CrossRef]

46. Yang, B.; Burns, N. Implications of postponement for the supply chain. Int. J. Prod. Res. 2003, 41, $2075-2090$. [CrossRef] 
47. Bulhoes, I.R.; Picchi, F.A. Continuous flow for structural design in prefabricated concrete structures. In Proceedings of the 16th Annual Conference of the International Group for Lean Construction, Manchester, UK, 16-18 July 2008; pp. 169-181.

48. Hopp, W.; Spearman, M. To pull or not to pull: What is the question? Manuf. Serv. Oper. Manag. 2004, 6, 133-148. [CrossRef]

49. Koskela, L. An Exploration towards a Production Theory and Its Application to Construction. Ph.D. Thesis, Helsinki University of Technology, VTT Technical Research Centre, Espoo, Finland, 2000.

50. Yin, R. Case Study Research: Design and Methods, 3rd ed.; SAGE Publications: Thousand Oaks, CA, USA, 2003.

51. Goodrum, P.M.; Shan, Y.; Suazo, A.; Haas, C.T.; Liu, J.; Caldas, C.H.; Banzekri, M.; Kim, J. Construction Productivity Research Program Phase IV; Construction Industry Institute: Austin, TX, USA, 2013.

52. Fleischman, R.; Lu, L.-W.; Viscomi, B.V.; Goodwin, K. Design and Implementation of ATLSS Connections. In Research Transformed into Practice; Colville, J., Amde, A.M., Eds.; ASCE Press: New York, NY, USA, 1995; pp. 108-119.

53. Viscomi, B.V.; Lu, L.; Perreira, N.D.; Michalerya, W.D.; Larrabee, A.B. Automated Erection of structures utilizing ATLSS connections and a robotic crane. Microcomput. Civ. Eng. 1995, 10, 309-323. [CrossRef]

54. Fleischman, R.B.; Viscomi, B.V.; Lu, L. ATLSS Connections-Concept, Development and Experimental Investigation, 1990. ATLSS Reports. ATLSS Report Number 91-02. Available online: http:/ / preserve.lehigh. edu/engr-civil-environmental-atlss-reports/165 (accessed on 4 December 2014).

55. Vincent Viscomi, B.; Michalerya, W.D.; Lu, L.-W. Automated construction in the ATLSS integrated building systems. Autom. Constr. 1994, 3, 35-43. [CrossRef]

56. Lincoln (Lincoln Electric). Waveform Control Technology. Available online: http://www.lincolnelectric. com/en-us/support/application-stories/Documents/articledocument (accessed on 29 October 2014).

57. Renz, B. Innovative Connections. Modern Steel Construction. AISC: Chicago, USA, August 2005. Available online: https://www.aisc.org/globalassets/modern-steel/archives/2005/08/2005v08_innovative_ connections.pdf (accessed on 21 October 2014).

58. Vrijhoef, R.; Koskela, L. The four roles of supply chain management in construction. Eur. J. Purch. Supply Manag. 2000, 6, 169-178. [CrossRef]

59. Ulrich, K. Fundamentals of product modularity. In Management of Design; Working Paper (Sloan School of Management); Springer: New York, USA, 1994; pp. 219-231.

60. Garlock, R.B.; Viscomi, B.V.; Lu, L. ATLSS Connections with Moment Capacity. ATLSS Reports. ATLSS Report. Paper 191. Available online: http://preserve.lehigh.edu/engr-civil-environmental-atlss-reports/191 (accessed on 4 December 2014).

61. CIF (Construction Innovation Forum). Prefab Moment/Space Frame System. 2007 Nova Award Nomination, 16. 2007. Available online: http://www.cif.org/awards/2007/16_-_Prefab_Moment-Space_Frame_System. pdf (accessed on 22 December 2014).

62. AISC (American Institute of Steel Construction). Prequalified Connections for Special and Intermediate Steel Moment Frames for Seismic Applications, ANSI/AISC 358-05; AISC: Chicago, IL, USA, 2016.

63. Stevenson, M.; Hendry, L.C.; Kingsman, B. A review of production planning and control: The applicability of key concepts to the make-to-order industry. Int. J. Prod. Res. 2005, 43, 869-898. [CrossRef]

64. Huang, C.C.; Kusiak, A. Modularity in design of products and systems. IEEE Trans. Syst. Man Cybern. Part A Syst. Hum. 1998, 28, 66-77. [CrossRef]

65. Rudberg, M.; Wikner, J. Mass customization in terms of the customer order decoupling point. Prod. Plan. Control 2004, 15, 445-458. [CrossRef]

(C) 2017 by the authors. Licensee MDPI, Basel, Switzerland. This article is an open access article distributed under the terms and conditions of the Creative Commons Attribution (CC BY) license (http:/ / creativecommons.org/licenses/by/4.0/). 